\title{
Hypoxia-Inducible Factor-1 $\alpha$ Mediates Hypoxia-Induced Delayed Neuronal Death That Involves p53
}

\author{
Marc W. Halterman, ${ }^{1,4}$ Craig C. Miller, ${ }^{2,4}$ and Howard J. Federoff ${ }^{3,4}$ \\ Departments of ${ }^{1}$ Microbiology and Immunology, ${ }^{2}$ Dermatology, and ${ }^{3}$ Neurology, ${ }^{4}$ Division of Molecular Medicine and \\ Gene Therapy, University of Rochester School of Medicine and Dentistry, Rochester, New York 14642
}

\begin{abstract}
Hypoxia-induced delayed neuronal death is known to require de novo gene expression; however, the molecular mediators that are involved remain undefined. The transcription factor hypoxia-inducible factor- $1 \alpha$ (HIF-1 $\alpha$ ), in addition to promoting the expression of adaptive genes under conditions of hypoxia, has been implicated as being a necessary component in p53mediated cell death in tumors. Using herpes ampliconmediated gene transfer in cortical neuronal cultures, we demonstrate that delivery of a dominant-negative form of HIF-1 $\alpha$
\end{abstract}

(HIFdn), capable of disrupting hypoxia-dependent transcription, reduces delayed neuronal death that follows hypoxic stress. In contrast, hypoxia-resistant p53-null primary cultures are not protected by HIFdn expression. These data indicate that, in hypoxic neurons, HIF- $1 \alpha$ and p53 conspire to promote a pathological sequence resulting in cell death.

Key words: HIF-1 $\alpha$; p53; hypoxia; neuron; delayed death; stroke
Delayed neuronal loss is a feature of postischemic damage present in the intact CNS as well as in dissociated neuronal cultures (Pulsinelli et al., 1982; Kirino et al., 1984; Du et al., 1996; Gottron et al., 1997). This activity involves the de novo expression of death genes, including proapoptotic genes of the $b c l-2$ family, which are central to the final and irreversible commitment to die (Wyllie et al., 1980; Korsmeyer, 1995; Reed, 1997). Although it is known that hypoxic stress can trigger neuronal death autonomously, the mechanisms governing the initiation of apoptotic signaling in the neuronal compartment remain undefined.

Under hypoxic or hypoglycemic conditions, mammalian tissues express adaptive gene products to satisfy metabolic demands. At the cellular level, hypoxia is sensed by an iron-containing moiety resulting in heterodimerization and nuclear translocation of the Per-ARNT-Sim (PAS) transcription factors hypoxia-inducible factor-1 $\alpha$ (HIF-1 $\alpha)$ and aryl hydrocarbon nuclear translocator (ARNT) (Goldberg et al., 1988; Srinivas et al., 1998). This HIF-1 complex promotes the expression of genes such as erythropoietin (EPO) by binding to hypoxia-responsive enhancer elements (HREs) (Blanchard et al., 1992; Guillemin and Krasnow, 1997). The necessity for these specific PAS family members to engender the adaptive response has been established via gene disruption. Loss of either HIF- $1 \alpha$ or ARNT in embryonic stem cells rendered them, in large part, incapable of transactivating hypoxiaand hypoglycemia-responsive targets (Maltepe et al., 1997; Iyer et al., 1998).

Under conditions of extreme hypoxia, the tumor suppressor p53 promotes growth arrest of dividing cells and apoptosis via the

Received Feb. 10, 1999; revised May 20, 1999; accepted May 28, 1999.

This work was supported by United States Public Health Service Grant HD31300 to H.J.F. and by fellowship support for M.W.H. (1F30MH12305-01). We thank Rita Giuliano for expert technical assistance; Drs. Arnold Levine, Gregg Semenza, and Kerry Blanchard for supplying important reagents; and Andy Brooks for providing timed pregnant mice.

Correspondence should be addressed to Dr. Howard J. Federoff, Department of Neurology, Box 673, University of Rochester School of Medicine and Dentistry, 601 Elmwood Avenue, Rochester, NY 14642.

Copyright (C) 1999 Society for Neuroscience $\quad 0270-6474 / 99 / 196818-07 \$ 05.00 / 0$ transactivation of genes such as $p 21^{\text {Waf1/Cip } 1}$ and bax. Conversely, human tumors harboring null or mutated p53 allele(s) exhibit reduced apoptosis under these conditions (Graeber et al., 1996; Levine, 1997; Carmeliet et al., 1998). Restoration of p53 function restrains cell growth and often reestablishes apoptotic potential (X. Chen et al., 1996). Aside from its pivotal role in the control of rapidly dividing tumor cells, p53 also has been implicated in the pathological response to ischemia exhibited by postmitotic neurons. p53 induction occurs within neurons after an ischemic insult and temporally precedes cell death (Li et al., 1994). Finally, mice deficient in p53 exhibit reduced infarct volumes after middle cerebral artery occlusion, further illustrating the functional role of p53 in ischemic neuronal death (Crumrine et al., 1994).

Recent observations provide evidence for a linkage between p53 and HIF-1 $\alpha$ in tumor cell lines. First, treatment with hypoxia (or hypoxic-mimetic agents) stabilizes p53 and HIF- $1 \alpha$ protein, resulting in enhanced target gene transcription (An et al., 1998; Blagosklonny et al., 1998). Second, removal of HIF-1 $\alpha$ from embryonic stem cells blocks the induction of p53 levels that follow extreme hypoxic exposure and attenuates stress-induced cell death (Carmeliet et al., 1998). Although a direct association between these proteins has not been proven, these data suggest that HIF- $1 \alpha$, either acting via a PAS partner or with $\mathrm{p} 53$, is involved in both adaptive and pathological transcriptional responses to stress. Here we investigate in neurons whether HIF-1 $\alpha$ signaling participates in hypoxia-induced delayed death. Our data demonstrate that, in cortical neurons, HIF-1 signaling activates delayed death in a p53-dependent manner, thus defining a new and important node of regulation of ischemic cell death.

\section{MATERIALS AND METHODS}

Reagents. Hep3B (American Type Culture Collection, Vienna, VA), SHEP-1, and SH-SY5Y (Ross et al., 1983) were grown in DMEM and $10 \%$ (v/v) fetal calf serum. Desferrioxamine mesylate, cobalt chloride, diphenyleneiodonium chloride (DPI), 2,3,5-triphenyltetrazolium chloride, polyethylenimine (PEI), and cytosine $\beta$-D-arabinofuranoside (AraC) were obtained from Sigma (St. Louis, MO). MK-801 and CNQX disodium were obtained from Research Biochemicals (Natick, MA). $\beta$-Galactosidase and luciferase activities were measured by using 
Galactolite (Tropix, Bedford, MA) and luciferase systems (Promega, Madison, WI).

Plasmid constructs. The plasmids pBS18 and pBS123, obtained from K. Blanchard (Louisiana State University, Shrevesport, LA), contain the 117 bp promoter and 123 bp enhancer elements derived from $5^{\prime}$ and $3^{\prime}$ untranslated regions of the human erythropoietin gene, cloned into pBluescript $\mathrm{KS}^{+}$(Blanchard et al., 1992). The construct 18-123F-pXP2 contains single copies of the enhancer and promoter elements cloned into the promoterless luciferase vector $\mathrm{pXP} 2$. The HSV-1 amplicon vectors HREprLac and $\mathrm{HRE}_{2}$ prLac were created by subcloning either one (HRE) or two $\left(\mathrm{HRE}_{2}\right)$ Pst $/$ Bam $\mathrm{HI}$ enhancer fragments from pBS123, along with a single BamHI/EagI promoter fragment from pBS18, into the promoterless amplicon reporter plasmid $\mathrm{pHSVOri}$ minLac. The dominant-negative HIF- $1 \alpha$ construct HSVHIFdn (HIFdn) was generated by PCR (fwd, 5'-CCGCTCGAGACCATGCGAAGTAAAGAATCTG-3'; rev, 5'-GGGGTACCTCATTTGTCAAAGAGGCT ACT- $3^{\prime}$ ), using the plasmid pCEP4/HIF- $1 \alpha$ as target (G. Semenza, Johns Hopkins, Baltimore, MD). The $1.1 \mathrm{~kb}$ product, lacking both the DNA binding and transactivation domain, was digested with XhoI and $K p n I$, cloned into the SalI and KpnI sites of the HSV-1 amplicon expression vector, and confirmed by sequencing. pRc/CMVhp53 and the transcriptionally defective mutant $\mathrm{p} 53^{22,23}$ (A. Levine, Princeton, NJ) were transferred to HSVprPuc as HindIII/XbaI fragments. The plasmids HSVbcl-2 (Bcl-2) and HSVLac (LacZ) are also HSVprPuc expression plasmids that have been described previously (Linnik et al., 1995).

Northern analysis. Cells were incubated under normoxic conditions $\left(21 \% \mathrm{O}_{2}\right)$, and total RNA was harvested with TRIZOL Reagent (Life Technologies, Gaithersburg, MD) according to the manufacturer's instructions. Mouse HIF- $1 \alpha$ and a 187 bp fragment corresponding to the mammalian 18s ribosomal subunit were cloned by RT-PCR from C57Bl6 kidney poly $\left(\mathrm{A}^{+}\right) \mathrm{RNA}$, using sequence-specific primers (mHIF: fwd, 5'-GGAAGACAACGCGGGCACCGAT-3' and rev, 5'-GGAGCTGTGAATGTGCTGTGATCTGGC-3'; 18s: fwd, 5'-CGGCTACCACATCCAAGGAA-3' and rev, 5'-GCTGGAATTACCGCGGCT-3'). EcoRI (1.6 $\mathrm{kb})$ and $\mathrm{Xba \textrm {I }}(1.5 \mathrm{~kb})$ fragments were used to probe human and mouse targets, respectively.

Herpes virus amplicon vectors. Viruses were prepared and titered as previously described (Geschwind et al., 1994). Helper titers ranged between 2 and $5 \times 10^{8} \mathrm{pfu} / \mathrm{ml}$. Amplicon titers for HSVLac and CMVLac (determined by X-gal histochemistry: $5 \mathrm{~mm}$ potassium ferricyanide, $5 \mathrm{~mm}$ potassium ferrocyanide, $0.02 \%$ NP- $40,0.01 \%$ sodium deoxycholic acid, $2 \mathrm{mM} \mathrm{MgCl}_{2}$, and $1 \mathrm{mg} / \mathrm{ml} \mathrm{X}$-gal dissolved in PBS) ranged between 1 and $3 \times 10^{8} \mathrm{bfu} / \mathrm{ml}$. Amplicon titers for HREprLac and $\mathrm{HRE}_{2}$ prLac stocks were determined by using a semiquantitative, limiting cycle PCR assay designed to detect amplicon-specific LacZ nucleic acid sequence recovered after virus infection of National Institutes of Health $3 \mathrm{~T} 3$ monolayers. HSV Lac virus of known titer for BFU standardization (fwd, 5'-GTGGCAGCATCAGGGGAAAACCTT-3'; rev, 5'-GAATTCCGCCGATACTGACGGGCT-3') used the following: $94^{\circ} \mathrm{C}$ for $2 \mathrm{~min}$ and $30 \mathrm{cycles}$ of $94^{\circ} \mathrm{C}$ for $30 \mathrm{sec}, 58^{\circ} \mathrm{C}$ for $45 \mathrm{sec}$, and $72^{\circ} \mathrm{C}$ for $45 \mathrm{sec}$.

In vivo reporter assays. All animal work described was performed in accordance with protocols approved by our institutional animal care committee. Under $2 \%$ halothane anesthesia eight female C57Bl6 mice received unilateral stereotaxic injections of HREprLac $(1.5 \mu \mathrm{l} ; 2.75 \times$ $10^{4}$ amplicon particles) and HSVLac $\left(1 \mu \mathrm{l} ; 1 \times 10^{5}\right.$ amplicon particles) at B1.0, L3.0, D2.0 (HRE) and B-1.6, L4.2, D3.0 (HSV). Then 4 d later, five mice were subjected to distal middle cerebral artery occlusion (MCAO) ipsilateral to the injection site, using an electrocautery stylus (Fine Science Tools, Foster City, CA) (Gueniau and Oberlander, 1997). Animals were killed $24 \mathrm{hr}$ after MCA occlusion, and $2 \mathrm{~mm}$ slices encompassing either injection sites or adjacent sections were harvested. Injected sections were homogenized in $500 \mu \mathrm{l}$ of lysis solution $(100 \mathrm{~mm}$ potassium phosphate, $\mathrm{pH} 7.8,0.2 \%$ Triton X-100, $1 \mathrm{~mm}$ DTT, $2 \mu \mathrm{g} / \mathrm{ml}$ aprotinin, and $0.2 \mathrm{mM}$ PMSF) and either analyzed for $\beta$-galactosidase activity or assayed by semiquantitative PCR to control for amplicon genome recovered during tissue harvesting. Adjacent sections were stained with $1 \%$ 2,3,5-triphenyltetrazolium in PBS for $45 \mathrm{~min}$ at $37^{\circ} \mathrm{C}$ to verify consistency in MCA occlusion and to ensure that the necrotic lesion did not extend beyond the injection site.

p53-Deficient mice and neuronal cultures. C57JB16 p53 heterozygous and homozygous knock-out litters were bred from founder mice (Taconic Farms, Germantown, NY) (Donehower et al., 1992). PCR-based genotyping for p53 was performed against p53 exons 5 and 6 (fwd, $5^{\prime}$ TACTCTCCTCCCCTCAATAAGCTA-3'; rev, 5'-CTGTCTTCCA-
GATACTCGGGATAC- $3^{\prime}$ ) and the neo ${ }^{\mathrm{r}}$ gene present in the targeting construct (fwd, 5'-CGGTTCTTTTTGTCAAGAC-3'; rev, 5'-ATCCTCGCCGTCGGGCATGC-3'). Cycling conditions included the following: $94^{\circ} \mathrm{C}$ for $2 \mathrm{~min} ; 30 \mathrm{cycles}$ of $94^{\circ} \mathrm{C}$ for $30 \mathrm{sec}, 55^{\circ} \mathrm{C}$ for $45 \mathrm{sec}$, and $72^{\circ} \mathrm{C}$ for $45 \mathrm{sec}$; and $72^{\circ} \mathrm{C}$ for $7 \mathrm{~min}$ (Timme and Thompson, 1994). Mixed cortical cultures from wild-type or p53-deficient newborn mice (embryonic day 14-16) were made as described (Gwag et al., 1995). Wild-type litters were processed in batches and distributed three hemispheres per 24-well plate. Mixed p53 litters were dissected individually, and each pair of cortices was distributed among 16 wells. Glia-free cortical cultures were produced by using the B27/Neurobasal formulation for plating and feeding (Brewer, 1995).

Oxygen glucose deprivation (OGD). Necrotic death was produced in days in vitro (DIV) 16-19 cultures by replacing the culture media with Earle's balanced salt solution (EBSS) [containing (in mM) 1.01 $\mathrm{NaH}_{2} \mathrm{PO}_{4}, 26.19 \mathrm{NaHCO}_{3}, 116.4 \mathrm{NaCl}, 0.81 \mathrm{MgSO}_{4}\left(7 \mathrm{H}_{2} \mathrm{O}\right), 5.37 \mathrm{KCl}$, $1.84 \mathrm{CaCl}_{2}$, and $1.1 \mathrm{D}$-glucose], followed by exposure to hypoxia $(0.5 \%$ $\mathrm{O}_{2} / 5 \% \mathrm{CO}_{2}$ at $37^{\circ} \mathrm{C}$ ) for $4 \mathrm{hr}$, using a triple gas incubator equipped with an internal $\mathrm{O}_{2}$ sensor (Forma Scientific, Marietta, OH). OGD was terminated by complete media replacement with fresh EBSS containing $25 \mathrm{~mm}$ glucose; neuron viability was assessed at $24 \mathrm{hr}$ qualitatively by examination under phase-contrast microscopy and quantitatively by cell counts after staining with trypan blue $(0.2 \%$ for $10 \mathrm{~min})$, as described (Goldberg and Choi, 1993). To produce delayed neuronal death in mixed (DIV 9-12) and purified B27 cultures (DIV 9), we replaced feed media with glucose-free EBBS containing $10 \mu \mathrm{M}$ MK-801 and $100 \mu \mathrm{M}$ CNQX before $110 \mathrm{~min}$ of hypoxic exposure $\left(0.5 \% \mathrm{O}_{2} / 5 \% \mathrm{CO}_{2}\right.$ at $\left.37^{\circ} \mathrm{C}\right)$. The addition of these glutamate receptor antagonists blocks necrotic neuronal death in this model. Delayed death is scored at $48 \mathrm{hr}$ by counting phase-bright neuronal somata that exclude trypan blue. This method has been shown by other investigators to correlate with other measures of cell death (Gwag et al., 1995; Gottron et al., 1997). Neuron viability was quantified by averaging the ratio of live (phase-bright, trypan bluenegative) neurons to the total number of neurons (phase-bright plus trypan blue-positive) counted from five non-overlapping fields under $200 \times$ magnification. Resultant values for a given treatment group represent five counts from each of four wells, producing a minimum of 2000 neurons per data point unless mentioned otherwise. Relative viability reflects the survival of infected hypoxic wells as compared with either averaged normoxic controls or HSVLac-infected hypoxic samples, as indicated.

\section{RESULTS}

\section{Hypoxia-responsive transcription is manifest in the CNS}

The expression and transcriptional activity of HIF- $1 \alpha$ have been documented in a wide variety of tissues. Although Northern analysis of rat and human total brain RNA has identified that HIF- $1 \alpha$ is expressed in the mammalian CNS (Wiener et al., 1996), neuron-specific expression has not been demonstrated. Using probes derived from human and mouse cDNA, we identified by Northern analysis the constitutive, normoxic expression of the $3.7 \mathrm{~kb}$ HIF-1 $\alpha$ transcript in a human hepatoma line (Hep3B), two human neuroblastoma lines (SHEP-1 and SY5Y), and in purified murine cortical neurons (Fig. 1A). These results are consistent with gel shift analyses that have identified enhanced HIF-1 binding to the HRE in purified neuronal extracts (Ruscher et al., 1998). Finally, transient transfection with an HREcontaining reporter construct resulted in hypoxia-dependent reporter gene activation in both neuroblastoma lines as well as in the Hep3B line, which is known to express high levels of HIF-1 $\alpha$ protein under hypoxic conditions (Fig. 1B).

To assess whether HIF-1-responsive signaling occurs in the ischemic CNS, we generated and tested initially in vitro an HREcontaining herpes amplicon reporter virus (HREprLac). Hep3B monolayers infected with HREprLac exhibited six- to 15-fold activation of reporter gene expression after hypoxia $\left(1 \% \mathrm{O}_{2}\right)$ or hypoxia-mimetics $100 \mu \mathrm{M} \mathrm{CoCl}_{2}$ and $100 \mu \mathrm{M}$ desferrioxamine (Fig. 2A). Additionally, hypoxic induction of HREprLac was 


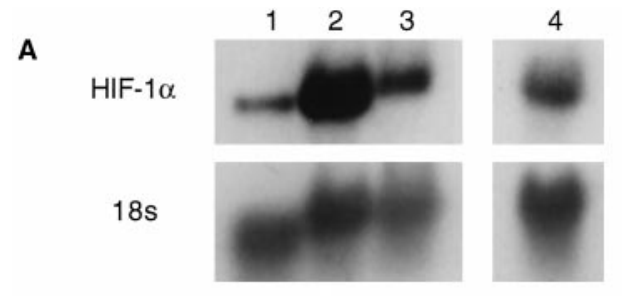

B
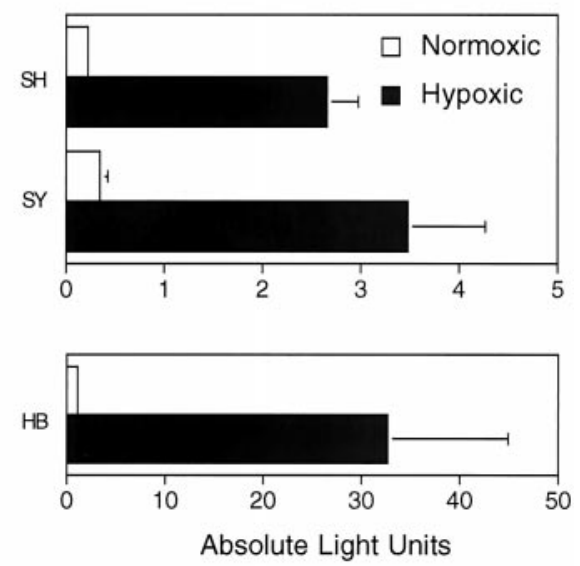

Figure 1. HIF- $1 \alpha$ activity in human neuroblastoma lines and cultured mouse primary cortical neurons. $A$, Normoxic cultured lines and primary neurons express HIF- $1 \alpha$ mRNA. Total RNA was harvested from the cell lines Hep3B (lane 1), SHEP-1 (lane 2), SY5Y (lane 3), and mouse cortical neurons (lane 4$)$. Samples $(20 \mu \mathrm{g})$ were probed by using human and mouse HIF- $1 \alpha$ cDNA fragments as described in Materials and Methods. $B$, HIF-1-responsive reporter plasmids are activated in hypoxic human neuroblastoma lines. SHEP-1 $(S H)$, SY5Y $(S Y)$, and Hep3B $(H B)$ cell lines were transfected with the HRE-containing reporter plasmid 18$123 \mathrm{~F}-\mathrm{pXP} 2$ and exposed to normoxic $\left(21 \% \mathrm{O}_{2}\right)$ or hypoxic $\left(1 \% \mathrm{O}_{2}\right)$ conditions. Then $36 \mathrm{hr}$ later the lysates were tested for hypoxia-dependent reporter activation by luciferase assay. Results from quadruplicate samples are presented in absolute light units $\times 1000$ (mean $\pm \mathrm{SD})$.

blocked by the flavoprotein inhibitor diphenyleneiodonium (DPI), shown previously to block HIF-1 complex activation (Gleadle et al., 1995). Similar hypoxic induction of HREprLac expression and blockade by DPI were observed in primary cortical cultures (data not shown). Reporter constructs containing either the human cytomegalovirus promoter (CMVlac, Fig. 2A, right) or the HSV immediate early $4 / 5$ promoter (HSVLac; data not shown) were unaffected by these treatments. To assess whether the HIF-1 complex is activated in the ischemic cortex, we used HREprLac and HSVLac reporter viruses in an in vivo model of permanent focal ischemia. The viruses were delivered by stereotaxic injection $\left(1 \times 10^{5} \mathrm{pfu}\right)$, as described in Materials and Methods. Injection coordinates were based on the distribution of the ischemic penumbra measured during preliminary studies performed in the C57/BL6 background. At $4 \mathrm{~d}$ after vector delivery the mice were subjected to ipsilateral middle cerebral artery occlusion (MCAO). Then $24 \mathrm{hr}$ later the injected cortices were harvested and analyzed. Postischemic cortical regions receiving HREprLac revealed a threefold increase in $\beta$-galactosidase activity (Fig. $2 B$, left). In contrast, our data suggest that HSVLac reporter activity declined (Fig. 2B, right). A similar decline in promoter activity has been observed with the CMV promoter in transduced ischemic rat cortex (Abe et al., 1997). Recovery of amplicon genomes from ischemic tissue did not differ as compared with nonischemic control animals (data not shown). Contributions to HRE and CMV activation from
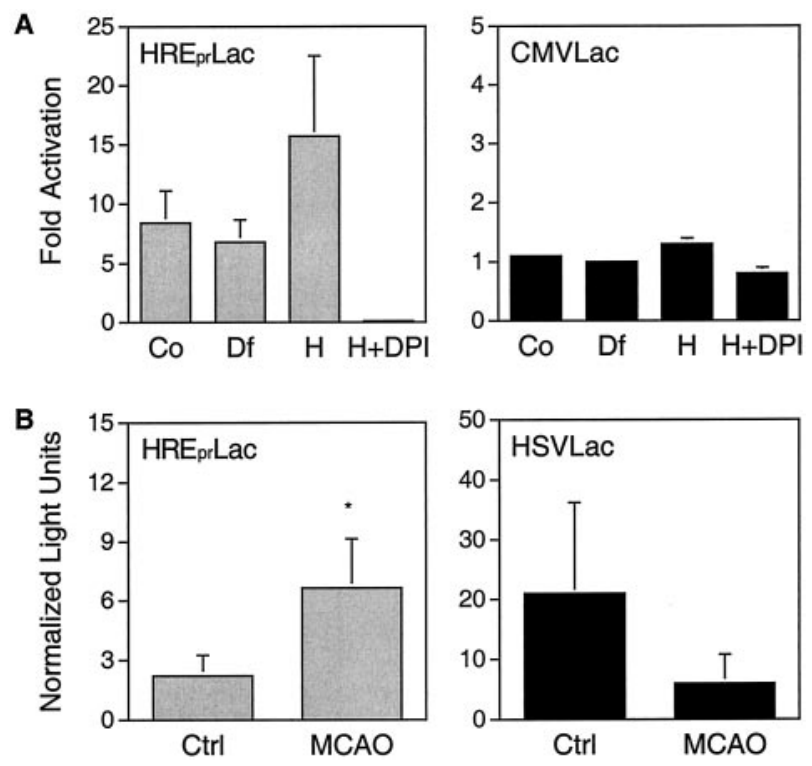

Figure 2. Middle cerebral artery occlusion (MCAO) induces expression from the HIF-1-responsive amplicon reporter HREprLac. A, Hep3B cultures were infected with HREprLac containing herpes particles at an MOI of 0.1 with HREprLac or CMVLac and exposed to $100 \mu \mathrm{M}$ cobalt chloride $(C o), 100 \mu \mathrm{M}$ desferrioxamine $(D f)$, hypoxia $\left(H ; 1 \% \mathrm{O}_{2}\right)$ or to hypoxia plus $5 \mu \mathrm{M}$ DPI $(H+D P I)$ for $36 \mathrm{hr}$. Quadruplicate samples were assayed for $\beta$-galactosidase activity. Data are presented as the fold activation of hypoxic samples relative to the average normoxic untreated control (mean $\pm \mathrm{SD}$ ). $B$, HIF-1-responsive reporter expression is increased in the ischemic cortex. At $4 \mathrm{~d}$ after the delivery of HREprLac and HSVLac virus, the mice were subjected to middle cerebral artery occlusion. Then $24 \mathrm{hr}$ later the injected coronal sections were harvested and analyzed as described in Materials and Methods. Values represent $\beta$-galactosidase activity per unit of viral genome recovered (mean $\pm \mathrm{SD}$ ) for control $(n=3)$ and stroked $(n=5)$ mice $\left({ }^{*} p<0.05\right.$ vs nonischemic control by unpaired two-tailed $t$ test).

infected cortical glia cannot be excluded; however, results from previous studies indicate that HSV vectors show a preference for infecting neurons. In aggregate, these experiments indicate that neurons possess the requisite machinery to respond and transduce the hypoxic signal. Also, whereas expression from a strong viral promoter is dampened, the transcriptional activity of the HIF-1 complex is increased in the ischemic penumbra $24 \mathrm{hr}$ after ischemia.

\section{Dominant-negative disruption of HIF-1 signaling attenuates delayed, but not rapid, neuronal death}

Others have shown that PAS deletion mutants, deficient in DNA binding and transactivation domains, suppress transcription from reporter plasmids containing HRE-like enhancer elements, yet they maintain the ability to heterodimerize with other PAS proteins (Lindebro et al., 1995; Forsythe et al., 1996). In a similar manner the amplicon expression plasmid HSVprHIFdn (HIFdn) was cloned by PCR and used in transient transfection reporter experiments to confirm the suppression of hypoxia-inducible reporter activity. Cultures were cotransfected with either HIFdn or pBluescript and the reporter $\mathrm{HRE}_{2}$ prLac (containing duplicated EPO enhancer elements), exposed to $36 \mathrm{hr}$ of hypoxia $\left(1 \% \mathrm{O}_{2}\right)$, and analyzed for increased $\beta$-galactosidase activity relative to normoxic $\left(21 \% \mathrm{O}_{2}\right)$ controls. Expression of HIFdn reduced $\mathrm{HRE}_{2}$ prLac induction by $90 \%$ (81.2 \pm 9.3 -fold to $7.6 \pm 1.8$-fold induction; mean $\pm \mathrm{SD}$ ), whereas expression of CMVLac was unaffected (Fig. 3). 

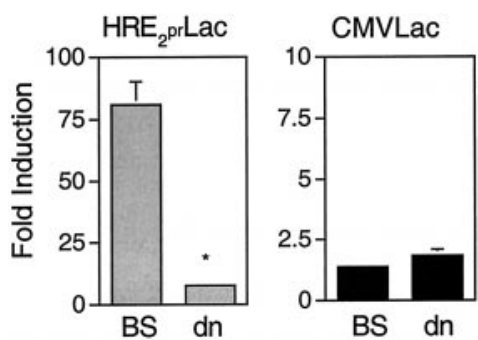

Figure 3. HIFdn attenuates expression from a HIF-1-sensitive reporter plasmid. Hep3B cells were transiently transfected with the reporter plasmids $\mathrm{HRE}_{2}$ prLac or CMVLac and either HIFdn $(d n)$ or pBS $(B S)$. Monolayers were exposed to control $\left(21 \% \mathrm{O}_{2}\right)$ or hypoxic $\left(1 \% \mathrm{O}_{2}\right)$ conditions for $36 \mathrm{hr}$ and analyzed for $\beta$-galactosidase activity. Data are presented as the fold induction of quadruplicate hypoxic samples (mean \pm SD) relative to normoxic transfected controls $\left({ }^{*} p<0.001\right.$ by unpaired two-tailed $t$ test).

Primary culture models of rapid and delayed neuronal death induced by OGD have been described previously (Monyer et al., 1989; Goldberg and Choi, 1993; Gwag et al., 1995). We sought to establish whether hypoxia-induced HIF-1 signaling promotes the expression of a death program in neurons. To this end, we tested the ability of HIFdn to provide neuroprotection, using both rapid and delayed paradigms. Primary cultures were infected at a multiplicity of infection (MOI) of 1.25, with amplicon viruses transducing the HIFdn, bcl-2, or lacZ genes and allowed to express. When infected with HSVLac at an MOI of 1.25, $68 \pm 3 \%$ of neurons in mixed cortical cultures were transduced as judged by $\mathrm{X}$-gal staining. At this dose, virus delivery alone does not produce observable toxicity $48 \mathrm{hr}$ after infection when scored by trypan blue staining (data not shown). At $20 \mathrm{hr}$ later the culture medium was replaced with EBSS containing $1.1 \mathrm{~mm}$ glucose, infected cultures were exposed to $0.5 \% \mathrm{O}_{2}$ conditions for $4 \mathrm{hr}$, and subsequently they were returned to normoxic, normoglycemic conditions. Neuron death in this paradigm is produced mainly by glutamate excitotoxicity and produces complete neuron lysis $24 \mathrm{hr}$ after the onset of hypoxia. In our paradigm, neither expression of $b c l-2$ nor dominant disruption of HIF-1 signaling was able to protect neurons from this insult (Fig. 4). Inclusion of the NMDA and AMPA receptor antagonists MK-801 and CNQX during the hypoxic period blocks the actions of glutamate and produces a delayed form of neuron death that is dependent on de novo gene expression as well as caspase activation (Gottron et al., 1997). Using this mixed culture, delayed death paradigm, we repeated the amplicon protection experiments. Although neuron viability was reduced in hypoxic HSVLac-infected cultures, hypoxic cortical neurons transduced with either HIFdn or $b c l-2$ were protected from delayed death (Fig. 5). Finally, delivery of HIFdn or $b c l-2$ to cortical cultures containing $<2 \%$ glia also protected hypoxic neurons from delayed death as compared with LacZtransduced cultures (Fig. 6). Taken together, these results suggest that, when exposed to hypoxic stress, cortical neurons undergo a delayed form of cell death that involves the activation of a HIF-1 complex within the neuronal compartment.

\section{HIFdn does not confer protection to p53-null, hypoxic cultures}

Because loss of p53 function reduces cortical infarct size (Crumrine et al., 1994) and increased p53 activity precedes apoptosis in postmitotic neurons in vivo (Li et al., 1994), we hypothesized that hypoxic neuronal apoptosis seen in our dissociated cortical culture system is dependent on p53 activity. By comparing the

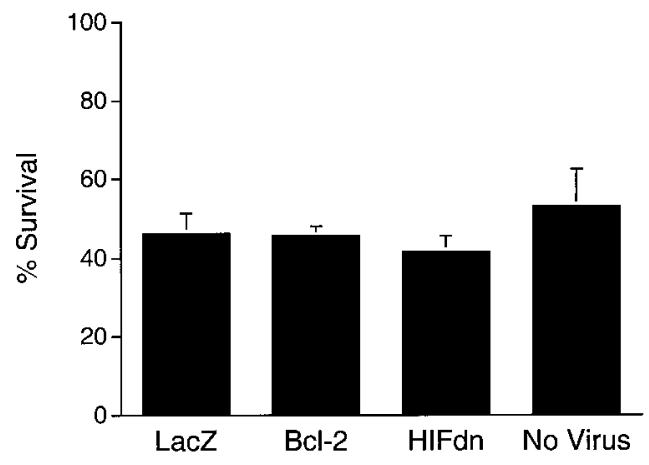

Figure 4. Expression of Bcl-2 or HIFdn does not protect cortical neurons from rapid cell death. Mixed cortical cultures (DIV 16-19) were infected with HSV amplicon viruses expressing $\beta$-galactosidase ( $L a c Z$ ), $\mathrm{Bcl}-2$, or HIFdn and allowed to incubate under normoxic conditions for $20 \mathrm{hr}$. Cultures were exposed to hypoxia $(0.5 \%)$ in EBSS (1.1 mu glucose) for $4 \mathrm{hr}$, returned to normoxic-normoglycemic conditions, and assessed for viability $24 \mathrm{hr}$ later by trypan blue exclusion. Data are expressed as the absolute percentage of surviving neurons (live/total) from infected and uninfected hypoxic wells (mean $\pm \mathrm{SD}$; based on an average of five measurements made from triplicate wells).

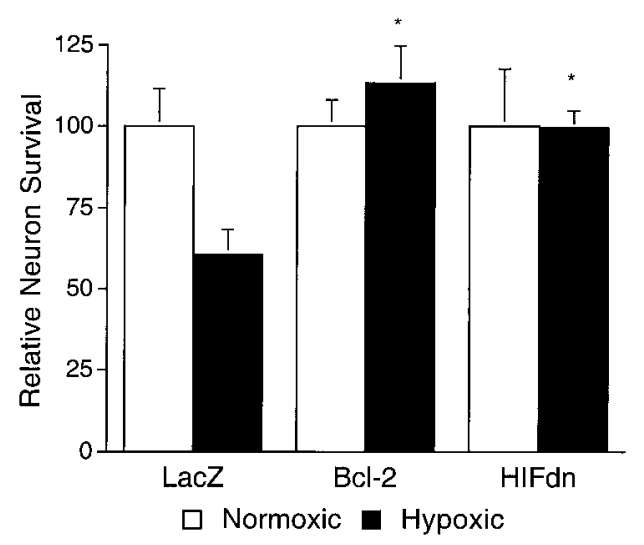

Figure 5. Disruption of HIF-1 signaling protects hypoxic primary cortical neurons from delayed death. Mixed cortical cultures (DIV 9-12) were infected with HSV amplicon viruses expressing $\beta$-galactosidase, $\mathrm{Bcl}-2$, or HIFdn and were allowed to express for $20 \mathrm{hr}$. Cultures were exposed to hypoxia $(0.5 \%)$ in glucose-free EBSS for $110 \mathrm{~min}$ in the presence of $10 \mu \mathrm{M}$ MK-801 and $100 \mu \mathrm{M}$ CNQX and returned to normoxic conditions. Cultures were refed with fresh EBSS (25 mM D-glucose) and assessed $46 \mathrm{hr}$ later by trypan blue exclusion. Data are expressed as the percentage of surviving hypoxic neurons relative to the survival of normoxic infected wells set to $100 \%$ (mean $\pm \mathrm{SD} ;{ }^{*} p<0.0001$ vs hypoxic LacZ control by unpaired two-tailed $t$ test).

viability of p53 knock-out cultures with wild-type controls after delayed OGD, we found that p53-null neurons were resistant to hypoxia-induced apoptosis (Fig. 7A). Complementation experiments were performed in p53-null cultures by delivering viruses expressing wild-type p53, a transcriptionally defective mutant $\mathrm{p} 53^{22,23}$, or $\beta$-galactosidase (LacZ) before hypoxic exposure. Although normoxic cultures were unaffected by p53 expression (data not shown), the introduction of wild-type p53 into hypoxic p53-null neurons was sufficient to reinstate cell death, whereas infection with the 22,23 mutant was not (Fig. $7 B$ ). Furthermore, HIFdn-infected cultures had reduced survival, equivalent to that in p53-infected wells, indicating that the protection conferred by HIFdn occurs only in the presence of p53 and that blockade of HIF-1 signaling in the p53-null background worsens neuron survival. 


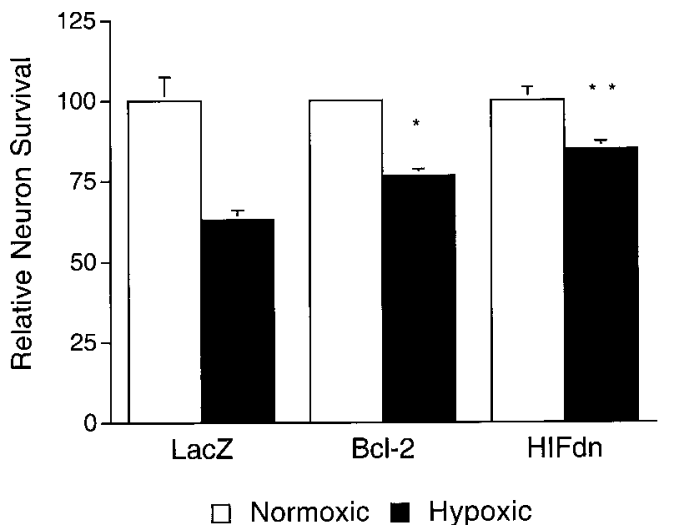

Figure 6. HIFdn protects hypoxic purified cortical neurons from delayed death. Cortical neurons, cultured in B27-supplemented Neurobasal medium, were infected with $\beta$-galactosidase, Bcl-2, or HIFdn-expressing amplicon viruses and allowed to express for $20 \mathrm{hr}$. Cultures were exposed to hypoxia $(0.5 \%)$ in glucose-free EBSS for $110 \mathrm{~min}$ in the presence of 10 $\mu \mathrm{M}$ MK-801 and $100 \mu \mathrm{M}$ CNQX and returned to normoxic conditions. Cultures were refed with fresh EBSS (25 mM D-glucose) and assessed for viability $46 \mathrm{hr}$ later by trypan blue exclusion. Data are expressed as the percentage of surviving hypoxic neurons relative to the survival of normoxic infected wells set to $100 \%$ (mean \pm SD; ${ }^{*} p<0.01$, ${ }^{* *} p<0.001$ vs hypoxic LacZ control by unpaired two-tailed $t$ test).

\section{DISCUSSION}

In response to hypoxic stress, cells regulate the expression of adaptive or pathological genes depending on the magnitude and duration of the stimulus. The adaptive response, engendered by the transcription factor $\mathrm{HIF}-1 \alpha$, is manifest at the cellular level via increased expression of glucose transporters and glycolytic enzymes, at the tissue level by enhancing angiogenesis, and at the organismal level by increasing erythropoiesis (Guillemin and Krasnow, 1997). Recent evidence suggests that components of the adaptive signaling response also elicit apoptosis in tumors, promoting the destruction of rapidly growing solid tumors that outstrip their vascularization. The data presented here demonstrate the participation of HIF-1 $\alpha$ in p53-dependent apoptosis in hypoxic cortical neurons.

HIF-1 binding activity in purified hypoxic neurons (Ruscher et al., 1998) and the regulation of HIF-1 transcriptional targets in hypoxic neuronal cell lines and in glial cultures have been demonstrated (Masuda et al., 1994; Krieg et al., 1998). Although not conclusive, these data suggest that HIF-1 activation is conserved throughout mammalian tissues, including cell types resident in the CNS. Our investigation revealed that, whereas both neuroblastoma lines express HIF- $1 \alpha$ mRNA at levels comparable to hepatic cell lines, the magnitude of the hypoxic transcriptional response in neural cells, measured using cis elements derived from the human erythropoietin enhancer region, is less robust. Explanations for this disparity include cell-specific differences in HIF-1 $\alpha$ protein stabilization and decreased affinity for the canonical HRE element caused by expression of alternate $\beta$-like PAS family members such as the neural-specific nPAS-2 (Zhou et al., 1997). Additionally, neurons may lack the factors expressed in the Hep3B line known to augment transcription from the erythropoietin promoter (Galson et al., 1994). Regardless of which mechanisms may contribute to these differences, our data support that human neuroblastoma lines, primary postmitotic neurons in culture, and cortical neurons and glia in vivo all possess the requisite machinery to respond to hypoxia at the transcriptional level.
A

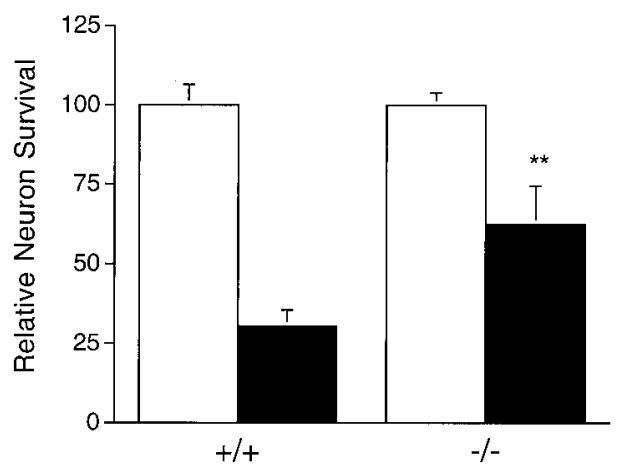

B

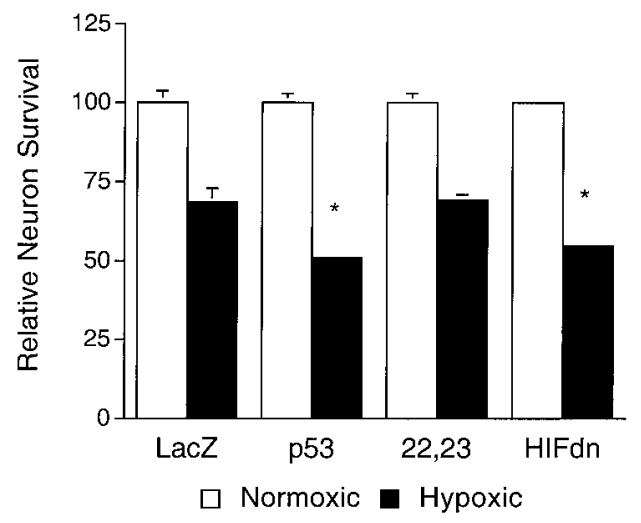

Figure 7. HIF-1 $\alpha$ promotes delayed neuronal death in a p53-dependent manner. $A$, p53-Deficient neurons are resistant to hypoxia-induced delayed neuronal death. Uninfected, wild-type $(+/+)$, or p53 homozygous null $(-/-)$ mixed cortical cultures were exposed to hypoxia $(0.5 \%)$ in glucose-free EBSS for $110 \mathrm{~min}$ in the presence of $10 \mu \mathrm{M}$ MK-801 and 100 $\mu \mathrm{M} C \mathrm{CNQX}$ and returned to normoxic conditions. Cultures were refed with fresh EBSS ( $25 \mathrm{~mm}$ D-glucose) and assessed for viability $46 \mathrm{hr}$ later by trypan blue exclusion. Data are expressed as the percentage of surviving hypoxic wild-type or knock-out neurons relative to normoxic controls set to $100 \%$ (mean $\pm \mathrm{SD} ;{ }^{*} p<0.0001$ vs hypoxic wild-type cultures by unpaired two-tailed $t$ test). $B$, Protection from delayed death by HIF-1 dominant-negative disruption requires p53. p53-Deficient mixed primary cultures were infected at an MOI of 1.25 , with amplicon viruses expressing $\beta$-galactosidase ( $L a c Z$ ), p53, the mutant $\mathrm{p} 53^{22,23}$, or HIFdn. Infected cultures were exposed to the delayed death paradigm and analyzed for survival as described in Figure $7 A$ (mean $\pm \mathrm{SD} ;{ }^{*} p<0.05$ comparing p53-, p53 ${ }^{22,23}$-, and HIFdn-infected cultures against hypoxic HSVLacinfected cultures).

We have shown that PAS factor-mediated hypoxic signaling can be disrupted by using a HIF-1 $\alpha$ dominant-negative amplicon construct. To test the anti-death activity of the dominantnegative, we used two oxygen glucose deprivation models known to elicit distinct forms of neuronal death. In a model of rapid neuronal death, HIFdn had no neuroprotective action. Strikingly, when delivered in the delayed neuronal death paradigm, expression of the dominant-negative prevented death, presumably via the disruption of HIF-1 mediated signaling. Confirmation of these findings in the glia-free culture system makes unlikely the possibility that the pro-death signal under study arises from the glial compartment. Furthermore, the survival-promoting activity of HIFdn appears to be as effective as transduction with the anti-apoptotic gene $b c l-2$.

The involvement of p53 in delayed neuronal death is supported by the reduction of infarct volumes measured in mice deficient in p53 (Crumrine et al., 1994) and by increased neuronal p53 ex- 
pression seen in the ischemic brain ( $\mathrm{Li}$ et al., 1994). Here we demonstrate that, in dissociated cortical cultures, delayed apoptotic death is affected significantly by p53 status. In hypoxic cultures devoid of p53, neurons survived to a greater extent than those carrying wild-type p53 alleles. To analyze further the requirement for p53 dependency for death, we transduced p53-null primary neuronal cultures with the mutant $\mathrm{p} 53^{22,23}$, which is defective in transactivation (Ludwig et al., 1996). Whereas restoration of $\mathrm{p} 53$ expression in the null background reestablished hypoxia-mediated cell death, transduction of $\mathrm{p} 53^{22,23}$ failed in this regard. Given that $\mathrm{p} 53^{22,23}$ is defective in its ability to induce target gene expression, the hypoxia-induced delayed neuronal death in wild-type cultures is likely attributable to the increased transactivation potential of p53. Our findings are supported by in vitro and in vivo studies that correlate the previous expression of Bax protein within cells fated to undergo delayed neuronal death (J. Chen et al., 1996; Xiang et al., 1998).

The role of 553 in HIF-1 pro-death signaling was clarified further with the use of p53-null cortical cultures. In contrast to its ability to protect wild-type neurons, HIFdn did not promote survival in p53-null neurons exposed to lethal levels of hypoxia. These data support the thesis that hypoxic activation of HIF-1 signaling depends on p53 for its apoptotic readout. Recent data from studies of HIF- $1 \alpha$ stabilization of p53 in tumor cell lines suggest a model in which the hypoxic activation of HIF-1 signaling can result in adaptive or pathological responses (Carmeliet et al., 1998). The only molecule known to discriminate between adaptive and pathological transcriptional readouts is $\mathrm{p} 53$. Indeed, the observation that p53 introduction in p53-null cell lines abrogates the transactivation of both the erythropoietin and VEGF promoters suggests a mechanism to regulate the adaptive and pathological response (Blagosklonny et al., 1998). Thus the simplest model posits that, under basal conditions in which p53 levels are low, hypoxia induces HIF-1 signaling via heterodimeric PAS family member interaction, leading to transcriptional activation of adaptive genes. However, under more sustained or severe hypoxic conditions, which result in HIF- $1 \alpha$ stabilization of and an overall increase in p53 levels, a new transcriptional complex involving both of these proteins is directed toward the transactivation of pathological genes such as bax.

The dominant-negative used in this study lacks both basic DNA binding and transcriptional activation domains yet retains the ability to interrupt PAS-mediated signaling. Although we assume that its activity is attributed to interactions between the dominant-negative and a participant in the HIF-1 pro-death pathway, we cannot identify definitively which molecule HIFdn targets. Because coimmunoprecipitation experiments have demonstrated that HIF- $1 \alpha$ and $\mathrm{p} 53$ associate under hypoxic conditions (An et al., 1998), it is plausible that the dominant-negative attenuates cell death by disrupting a putative HIF- $1 \alpha /$ p53 complex. However, the alternative that HIFdn interrupts necessary heterodimerization interactions between wild-type HIF-1 $\alpha$ and a neuronal $\beta$-partner, upstream of HIF- $1 \alpha / \mathrm{p} 53$ interaction, cannot be excluded. In the absence of p53 or under circumstances in which p53 stabilization is blocked, hypoxia would be expected solely to direct the transcription of adaptive or protective genes. Our observation that dominant-negative disruption of HIF-1 signaling within p53-null neurons reduces neuron survival is consistent with the attenuation of a HIF- $1 \alpha / \mathrm{HIF}-1 \beta$-mediated neuroprotective transcriptional response.

In conclusion, we have demonstrated that HIF- $1 \alpha$ signaling in primary cortical neurons elicits delayed death involving the par- ticipation of p53. In our paradigm p53 and HIF-1 $\alpha$ govern which fate, adaptive or pathological, the neuron will follow. Under mild conditions, hypoxia induces HIF-1 signaling via heterodimeric PAS family member interactions, leading to transcriptional activation of adaptive genes. However, under conditions of sustained metabolic stress, HIF- $1 \alpha$ stabilization increases cellular p53 levels driving the transactivation of pathological genes. It remains to be determined whether other neuron-specific $\alpha$ - or $\beta$-like PAS molecules participate in this pro-death activity. Implicit in this model is the testable notion of an integrative hypoxia-sensing mechanism that not only determines which fate, adaptive or pathological, the cell will follow but also provides a rational regulatory node at which to direct neuron-sparing therapeutics.

\section{REFERENCES}

Abe K, Setoguchi Y, Hayashi T, Itoyama Y (1997) In vivo adenovirusmediated gene transfer and the expression in ischemic and reperfused rat brain. Brain Res 763:191-201.

An WG, Kanekal M, Simon MC, Maltepe E, Blagosklonny MV, Neckers LM (1998) Stabilization of wild-type p53 by hypoxia-inducible factor $1 \alpha$. Nature 392:405-408.

Blagosklonny MV, An WG, Romanova LY, Trepe J, Fojo T, Neckers L (1998) p53 inhibits hypoxia-inducible factor-stimulated transcription. J Biol Chem 273:11995-11998.

Blanchard KL, Acquaviva AM, Galson DL, Bunn HF (1992) Hypoxic induction of the human erythropoietin gene: cooperation between the promoter and enhancer, each of which contains steroid receptor response elements. Mol Cell Biol 12:5373-5385.

Brewer GJ (1995) Serum-free B27/Neurobasal medium supports differentiated growth of neurons from the striatum, substantia nigra, septum, cerebral cortex, cerebellum, and dentate gyrus. J Neurosci Res 42:674-683.

Carmeliet P, Dor Y, Herbert J-M, Fukumura D, Brusselmans K, Dewerchin M, Neeman M, Bono F, Abramovitch R, Maxwell P, Koch C, Ratcliffe P, Moons L, Jain R, Collen D, Keshet E (1998) Role of HIF- $1 \alpha$ in hypoxia-mediated apoptosis, cell proliferation, and tumour angiogenesis. Nature 394:485-490.

Chen J, Zhu RL, Nakayama M, Kawaguchi K, Jin K, Stetler RA, Simon RP, Graham SH (1996) Expression of the apoptosis-effector gene, $B a x$, is up-regulated in vulnerable hippocampal CA1 neurons following global ischemia. J Neurochem 67:64-71.

Chen X, Ko LJ, Jayaraman L, Prives C (1996) p53 levels, functional domains, and DNA damage determine the extent of the apoptotic response of tumor cells. Genes Dev 10:2438-2451.

Crumrine RC, Thomas AL, Morgan PF (1994) Attenuation of p53 expression protects against focal ischemic damage in transgenic mice. J Cereb Blood Flow Metab 14:887-891.

Donehower LA, Harvey M, Slagle BL, McArthur MJ, Montgomery Jr CA, Butel JS, Bradley A (1992) Mice deficient for p53 are developmentally normal but susceptible to spontaneous tumours. Nature 356:215-221.

Du C, Hu R, Csernansky CA, Hsu CY, Choi DW (1996) Very delayed infarction after mild focal cerebral ischemia: a role for apoptosis? J Cereb Blood Flow Metab 16:195-201.

Forsythe JO, Jiang B-H, Iyer NV, Agani F, Leung SW, Koos RD, Semenza GL (1996) Activation of vascular endothelial growth factor gene transcription by hypoxia-inducible factor 1. Mol Cell Biol 16:4604-4613.

Galson DL, Blanchard KL, Fandrey J, Goldberg MA, Bunn HF (1994) $\mathrm{C}$ is elements that regulate the erythropoietin gene. Ann NY Acad Sci 718:21-30.

Geschwind MD, Lu B, Federoff HF (1994) Viral transfection of intrinsic cells within the brain. Expression of neurotrophic genes from HSV-1 vectors: modifying neuronal phenotype. Providing pharmacological access to the brain. In: Methods in neurosciences (Conn P, ed), pp 462-482. Orlando, FL: Academic.

Gleadle JM, Ebert BL, Ratcliffe PJ (1995) Diphenylene iodonium inhibits the induction of erythropoietin and other mammalian genes by hypoxia. Implications for the mechanism of oxygen sensing. Eur J Biochem 234:92-99.

Goldberg MA, Dunning SP, Bunn HF (1988) Regulation of the eryth- 
ropoietin gene: evidence that the oxygen sensor is a heme protein. Science 242:1412-1415.

Goldberg MP, Choi DW (1993) Combined oxygen and glucose deprivation in cortical cell culture: calcium-dependent and calciumindependent mechanisms of neuronal injury. J Neurosci 13:3510-3524.

Gottron FJ, Ying HS, Choi DW (1997) Caspase inhibition selectively reduces the apoptotic component of oxygen glucose deprivationinduced cortical neuronal cell death. Mol Cell Neurosci 9:159-169.

Graeber TG, Osmanian C, Jacks T, Housman DE, Koch CJ, Lowe SW, Giaccia AJ (1996) Hypoxia-mediated selection of cells with diminished apoptotic potential in solid tumours. Nature 379:88-91.

Gueniau C, Oberlander C (1997) The kappa opioid agonist niravoline decreases brain edema in the mouse middle cerebral artery occlusion model of stroke. J Pharmacol Exp Ther 282:1-6.

Guillemin K, Krasnow MA (1997) The hypoxic response: huffing and HIFing. Cell 89:9-12.

Gwag BJ, Lobner D, Koh JY, Wie MB, Choi DW (1995) Blockade of glutamate receptors unmasks neuronal apoptosis after oxygen glucose deprivation in vitro. Neuroscience 68:615-619.

Iyer NV, Kotch LE, Agani F, Leung SW, Laughner E, Wenger RH, Gassmann M, Gearhart JD, Lawler AM, Yu AY, Serrenza G (1998) Cellular and developmental control of $\mathrm{O}_{2}$ homeostasis by hypoxiainducible factor $1 \alpha$. Genes Dev 12:149-162.

Kirino T, Tamura A, Sano K (1984) Delayed neuronal death in the rat hippocampus following transient forebrain ischemia. Acta Neuropathol (Berl) 64:139-147.

Korsmeyer SJ (1995) Regulators of cell death. Trends Genet 11:101-105.

Krieg M, Marti HH, Plate KH (1998) Coexpression of erythropoietin and vascular endothelial growth factor in nervous system tumors associated with von Hippel-Lindau tumor suppressor gene loss of function. Blood 92:3388-3393.

Levine AJ (1997) p53, the cellular gatekeeper for growth and division. Cell 88:323-331.

Li Y, Chopp M, Zheng G, Zaloga C, Niewhuis L, Gautam S (1994) p53 immunoreactive protein and p53 mRNA expression after transient middle cerebral artery occlusion in rats. Stroke 25:849-856.

Lindebro MC, Poellinger L, Whitelaw ML (1995) Protein-protein interaction via PAS domains: role of the PAS domain in positive and negative regulation of the bHLH/PAS dioxin receptor-ARNT transcription factor complex. EMBO J 14:3528-3539.

Linnik MD, Zahos P, Geschwind MS, Federoff HJ (1995) Expression of bcl-2 from a defective herpes simplex virus-1 vector limits neuronal death in focal cerebral ischemia. Stroke 26:1670-1675.
Ludwig RL, Bates S, Vousden KH (1996) Differential activation of target cellular promoters by p53 mutants with impaired apoptotic function. Mol Cell Biol 16:4952-4960.

Maltepe E, Schmidt JV, Baunoch D, Bradfield CA, Simon MC (1997) Abnormal angiogenesis and responses to glucose and oxygen deprivation in mice lacking the protein ARNT. Nature 386:403-407.

Masuda S, Okano M, Yamagishi K, Nagao M, Ueda M, Sasaki R (1994) A novel site of erythropoietin production: oxygen-dependent production in cultured rat astrocytes. J Biol Chem 269:19488-19493.

Monyer H, Goldberg MP, Choi DW (1989) Glucose deprivation neuronal injury in cortical culture. Brain Res 483:347-354.

Pulsinelli WA, Brierley JB, Plum F (1982) Temporal profile of neuronal damage in a model of transient forebrain ischemia. Ann Neurol 11:491-498.

Reed JC (1997) Double identity for proteins of the Bcl-2 family. Nature 387:773-776.

Ross RA, Spengler BA, Biedler JL (1983) Coordinate morphological and biochemical interconversion of human neuroblastoma cells. J Natl Cancer Inst 71:741-747.

Ruscher K, Isaev N, Trendelenburg G, Weih M, Iurato L, Meisel A, Dirnagl U (1998) Induction of hypoxia-inducible factor 1 by oxygen glucose deprivation is attenuated by hypoxic preconditioning in rat cultured neurons. Neurosci Lett 254:117-120.

Srinivas V, Zhu X, Salceda S, Nakamura R, Caro J (1998) Hypoxiainducible factor- $1 \alpha$ (HIF- $1 \alpha)$ is a non-heme iron protein. Implications for oxygen sensing. J Biol Chem 273:18019-18022.

Timme TL, Thompson TC (1994) Rapid allelotype analysis of p53 knock-out mice. Biotechniques 17:460, 462-463.

Wiener CM, Booth G, Semenza GL (1996) In vivo expression of mRNAs encoding hypoxia-inducible factor 1 . Biochem Biophys Res Commun 225:485-488

Wyllie AH, Kerr JF, Currie AR (1980) Cell death: the significance of apoptosis. Int Rev Cytol 68:251-306.

Xiang H, Kinoshita Y, Knudson CM, Korsmeyer SJ, Schwartzkroin PA, Morrison RS (1998) Bax involvement in p53-mediated neuronal cell death. J Neurosci 18:1363-1373.

Zhou YD, Barnard M, Tian H, Li X, Ring HZ, Francke U, Shelton J, Richardson J, Russell DW, McKnight SL (1997) Molecular characterization of two mammalian bHLH-PAS domain proteins selectively expressed in the central nervous system. Proc Natl Acad Sci USA 94:713-718. 